\title{
PENGARUH PUPUK ORGANIK BERKADAR BESI TINGGI TERHADAP PERTUMBUHAN DAN PRODUKSI PADI SAWAH
}

\author{
EFFECT OF ORGANIC FERTILIZER WITH HIGH IRON CONTENT \\ ON THE GROWTH AND PRODUCTION OF WETLAND RICE
}

\author{
Triyani Dewi ${ }^{1}$, Iswandi Anas ${ }^{2}$, Suwarno $^{2}$, dan Dedi Nursyamsi ${ }^{3}$
}

Diterima 1 November 2012, disetujui 28 Juni 2013

\begin{abstract}
The application of chemical fertilizers is costly and gradually lead to the environmental problems. Organic residue recycling is becoming an increasingly important aspect of environmentally sound sustainable agriculture. Organic content of these soils are mostly very low, while it is widely know that organic matter is very important to keep physical, chemical, and biological properties of soil as well as soil productivity. The objectives of the study were to know effect of organic fertlizer that high iron content on growth and production paddy rice. Pot experiment was conducted on May to November 2011 in green house. This experiment using a randomized complete block design with two factors; the types of soil (Endoaquert, Tropaquept, and Hapludult) and organic fertilizer enriched with $\mathrm{Fe}\left(\mathrm{FeCl}_{3}\right)$ in various level. Each treatment was replicated three times. The results showed that the organic fertilizer enriched with iron up to $64000 \mathrm{mg}^{.} \mathrm{kg}^{-1}$ didn't significantly effect on the growth and rice production. Application of organic fertilizer in Tropaquept Sukamandi can increase significantly on height plant, number of tiller, dry weight of grain and 1000-grain weight.
\end{abstract}

Keywords: Organic fertilizer, iron content, rice production

\section{PENDAHULUAN}

Pupuk organik sangat bermanfaat bagi peningkatan produksi pertanian baik kualitas maupun kuantitas, mengurangi pencemaran lingkungan, dan meningkatkan kualitas lahan secara berkelanjutan. Peran pupuk organik dalam hal ini dapat memperbaiki sifat fisika, kimia, dan biologi tanah, serta penyumbang unsur hara yang sangat berarti yang tidak tercakup dalam pupuk anorganik. Pupuk organik juga merupakan agen yang efektif untuk memperbaiki kualitas tanah dalam jangka panjang. Sebagai tambahan, pupuk

\footnotetext{
${ }^{1)}$ Balai Penelitian Lingkungan Pertanian, Pati. email:triyanidewi@yahoo.com

2) Jurusan Ilmu Tanah dan Sumberdaya Lahan, Faperta IPB

${ }^{3)}$ Balai Penelitian Pertanian Lahan Rawa, Banjarbaru
}

organik dari limbah dapat mengurangi biaya dalam produksi pertanian (Boonsiri et al., 2009).

Pupuk organik menurut Suriadikarta et al., (2005) adalah pupuk yang sebagian besar atau seluruhnya terdiri atas bahan organik yang berasal dari tanaman dan atau hewan yang telah melalui proses rekayasa, dapat berbentuk padat atau cair yang digunakan untuk mensuplai bahan organik untuk memperbaiki sifat fisika, kimia, dan biologi tanah.

Menurut Peraturan Menteri Pertanian No. 70/ Permentan/SR.140/10/2011 tentang pupuk organik, pupuk hayati, dan pembenah tanah, kadar besi $(\mathrm{Fe})$ merupakan salah satu parameter dalam persyaratan teknis yang harus dipenuhi dalam 
pupuk organik. Pupuk organik berkualitas baik khususnya pupuk organik granul, apabila kadar Fe-total nya tidak melebihi $9.000 \mathrm{mg} \cdot \mathrm{kg}^{-1}$. Penetapan angka ini tampaknya mempunyai pertimbangan agar pupuk organik padat yang ditambahkan ke dalam tanah tidak sampai meracuni tanaman, terutama untuk tanaman padi sawah. Kelarutan besi dalam kondisi anaerobik sangat tinggi, sehingga ada kekhawatiran bila kadar Fe dalam pupuk organik melebihi angka tersebut berpotensi meracuni tanaman bila pupuk organik ditambahkan ke dalam tanah.

Unsur Fe termasuk unsur hara mikro yang diperlukan tanaman dalam jumlah sedikit tapi bila berlebihan dalam tanah maka akan berpotensi meracuni tanaman. Penelitian mengenai unsur mikro khususnya Fe dalam pupuk organik hingga saat ini belum banyak dilakukan dan hingga saat ini belum terdengar adanya laporan bahwa tanaman padi sawah mengalami keracunan besi akibat dari penggunaan pupuk organik. Penelitian ini bertujuan untuk mengetahui pengaruh pupuk organik berkadar $\mathrm{Fe}$ tinggi terhadap pertumbuhan dan produksi padi sawah.

\section{BAHAN DAN METODE}

Penelitian ini dilaksanakan di rumah kasa Tanah Baru, Bogor pada bulan Mei-November 2011. Analisis pupuk organik dan tanah dilakukan di Laboratorium Terpadu Balai Penelitian Lingkungan Pertanian, Pati, Jawa Tengah.

Rancangan percobaan yang digunakan dalam penelitian adalah Rancangan Acak Kelompok (RAK) pola faktorial yang diulang sebanyak tiga kali. Faktor pertama adalah jenis tanah yaitu: Endoaquert Ngawi $\left(\mathrm{T}_{1}\right)$, Tropaquept Sukamandi $\left(\mathrm{T}_{2}\right)$ dan Hapludult Pandeglang $\left(\mathrm{T}_{3}\right)$, dan faktor kedua adalah berbagai takaran besi yang ditambahkan ke dalam pupuk organik, yaitu: kontrol/tanpa penambahan pupuk organik $\left(\mathrm{F}_{0}\right)$, penambahan pupuk organik $\left(\mathrm{F}_{1}\right)$, pupuk organik dan $8.000 \mathrm{mg} \cdot \mathrm{kg}^{-1} \mathrm{Fe}\left(\mathrm{F}_{2}\right)$, pupuk organik dan 16.000 mg.kg ${ }^{-1} \mathrm{Fe}\left(\mathrm{F}_{3}\right)$, pupuk organik dan $24.000 \mathrm{mg} . \mathrm{kg}$ -
${ }^{1} \mathrm{Fe}\left(\mathrm{F}_{4}\right)$, pupuk organik dan $32.000 \mathrm{mg} \cdot \mathrm{kg}^{-1} \mathrm{Fe}$ $\left(\mathrm{F}_{5}\right)$, pupuk organik dan $64.000 \mathrm{mg} \cdot \mathrm{kg}^{-1} \mathrm{Fe}\left(\mathrm{F}_{6}\right)$.

Contoh tanah dikeringanginkan, kemudian ditumbuk dan diayak dengan ayakan $4 \mathrm{~mm}$, lalu ditimbang setara dengan 10 per pot. Pupuk organik yang digunakan berbentuk granul yang diperkaya dengan $\mathrm{Fe}$ yang berasal dari $\mathrm{FeCl}_{3}$ dengan cara ditambah $\mathrm{FeCl}_{3}$ sesuai dengan takaran dalam perlakuan, lalu dicampur hingga homogen. Setelah itu, pupuk organik tersebut diaplikasikan ke dalam pot-pot yang sudah disiapkan dengan dosis 1 ton.ha ${ }^{-1}$ atau setara dengan 5 g.pot ${ }^{-1}$. Tanah lalu digenangi air dan ketinggian air dipertahankan sekitar $3 \mathrm{~cm}$, lalu diinkubasi selama tujuh hari. Tanah diberi pupuk dasar dengan dosis masingmasing 150 mg.kg ${ }^{-1} \mathrm{~N}, 100$ mg.kg-1 $\mathrm{P}_{2} \mathrm{O}_{5}$ dan 75 mg.kg- ${ }^{-1} \mathrm{~K}_{2} \mathrm{O}$ masing-masing berasal dari urea, SP-36, dan KCl.

Benih padi yang digunakan varietas IR 64 karena varietas padi ini tergolong peka terhadap kandungan besi (Suhartini, 2004)., disemai terlebih dahulu setelah 21 HSS ( 9 hari setelah semai), bibit padi dipindah ke dalam pot percobaan dan ditanam sebanyak 2 bibit per pot, selanjutnya tanaman dipelihara hingga panen.

Pengamatan tinggi tanaman dan jumlah anakan dilakukan sepuluh hari sekali hingga menjelang panen. Tanaman padi dipanen umur 105-110 HST kemudian dilakukan pengamatan komponen produksi yaitu bobot jerami kering, bobot gabah kering panen, dan bobot 1000 butir. Contoh tanah sebelum tanam diambil untuk dianalisis sifat fisika dan kimianya meliputi: tekstur tanah, $\mathrm{pH}_{2} \mathrm{O}$ dan $\mathrm{pH} \mathrm{KCl,} \mathrm{C-organik,} \mathrm{N-total,} \mathrm{P} \mathrm{dan} \mathrm{K} \mathrm{terekstrak}$ HCl 25 persen, basa-basa dapat ditukar, KTK, kadar Fe-total, dan kadar Fe terekstrak DTPA.

\section{HASIL DAN PEMBAHASAN}

\section{Kadar Hara Pupuk Organik}

Pupuk organik yang digunakan berbentuk granul, sifat-sifat pupuk organik tersaji pada Tabel 1 . 
Secara umum, pupuk organik yang digunakan belum memenuhi kriteria persyaratan teknis sesuai dengan Permentan No. 70 Tahun 2011. Nilai pH sebesar 6,77, kandungan C-organik sebesar 14,77 persen dengan $\mathrm{N}$-total 0,44 persen, rasio $\mathrm{C} / \mathrm{N}$ tergolong tinggi 33,57 jauh diatas persyaratan mutu pupuk organik yaitu sebesar 1525. Kadar $\mathrm{P}_{2} \mathrm{O}_{5}$ dan $\mathrm{K}_{2} \mathrm{O}$ masing-masing sebesar 1,0 dan 6,43 persen. Kadar Fe-tersedia dan Fetotal masing-masing sebesar 14,87 dan 2614

${ }^{-1}$, nilai tersebut sudah sesuai syarat mutu sebagai pupuk organik. Kadar logam berat $\mathrm{Pb}$ dan Cd masing-masing sebesar 25,48 dan 7,82 mg.kg- ${ }^{-1}$.

\section{Karakteristik Tanah}

Ketiga jenis tanah yang digunakan pada umumnya bertekstur halus, dengan kandungan fraksi liat $>50$ persen (Tabel 2). Kadar C-organik organik tanah Tropaquept tergolong sedang, sedangkan tanah Endoaquert dan Hapludult tergolong rendah (<2\%). Suhardjo et al., (1993) mengemukakan bahwa kadar bahan organik dalam tanah dengan mudah dan cepat dapat berkurang karena erosi, oksidasi atau perombakan oleh jasad mikro tanah. Reaksi tanah ( $\mathrm{pH}$ aktual) tergolong masam (4,90 $-5,19)$.

Menurut kriteria penilaian hasil analisis tanah menurut Balai Penelitian Tanah (2005), kadar N total tanah Tropaquept sedang, sedangkan tanah Hapludult dan Endoaquert tergolong rendah yaitu masing-masing sebesar 0,17 dan 0,15 persen. Kadar Pdan K total pada Tropaquept dan Hapludult tergolong sangat tinggi. Pada Endoaquert, P-total tergolong sedang dan K-total tergolong tinggi. $\mathrm{P}$ tersedia (Bray I) Tropaquept tergolong tinggi, Hapludult tergolong sangat rendah, dan Endoaquert tergolong sangat tinggi. Endoaquert yang diambil dari Ngawi memiliki Ca dan $\mathrm{Mg}$ tergolong tinggi masing-masing sebesar 57,93 dan 9,7 cmol(+)/kg. Ini disebabkan karena bahan induknya berasal dari sedimen liat berkapur, drainase tanah buruk sehingga kadar $\mathrm{Ca}, \mathrm{Mg}$, dan Si tinggi yang mendukung terbentuknya tanah Vertisol.

Tabel 1. Sifat-sifat pupuk organik

\begin{tabular}{|c|c|c|c|c|}
\hline Parameter & Satuan & Metode & Nilai & $\begin{array}{c}\text { Kriteria } \\
\text { Permentan No. } 70 \\
\text { Tahun } 2011 \\
\end{array}$ \\
\hline Kadar Air & $\%$ & Gravimetri & 18,15 & $8-20$ \\
\hline $\mathrm{pH}$ & & $\mathrm{pH}$ meter & 6,77 & $4-9$ \\
\hline C-organik & $\%$ & Walkley and Black & 14,77 & $>15$ \\
\hline N-total & $\%$ & Kjeldahl & 0,44 & $>4$ \\
\hline $\mathrm{C} / \mathrm{N}$ & & & 33,57 & $15-25$ \\
\hline $\mathrm{P}_{2} \mathrm{O}_{5}$ & $\%$ & $\mathrm{HNO}_{3}: \mathrm{HClO}_{4}$ & 1,00 & $>4$ \\
\hline $\mathrm{K}_{2} \mathrm{O}$ & $\%$ & $\mathrm{HNO}_{3}: \mathrm{HClO}_{4}$ & 6,43 & $\geq 4$ \\
\hline Fe-tersedia & $\mathrm{mg} \mathrm{kg}^{-1}$ & Ektsrak DTPA & 14,87 & $\leq \overline{5} 00$ \\
\hline Fe-total & $\mathrm{mg} \mathrm{kg}^{-1}$ & $\mathrm{HNO}_{3}: \mathrm{HClO}_{4}$ & 2614 & $\leq 9000$ \\
\hline Logam berat $\mathrm{Pb}$ & $\mathrm{mg} \mathrm{kg}^{-1}$ & $\mathrm{HNO}_{3}: \mathrm{HClO}_{4}$ & 25,48 & $\leq 50$ \\
\hline Logam berat $\mathrm{Cd}$ & $\mathrm{mg} \mathrm{kg}^{-1}$ & $\mathrm{HNO}_{3}: \mathrm{HClO}_{4}$ & 7,82 & $\leq 2$ \\
\hline
\end{tabular}


Pengaruh pupuk organik berkadar besi tinggi terhadap pertumbuhan dan produksi padi sawah (Triyani Dewi)

Tabel 2. Karakteristik tanah yang digunakan dalam percobaan rumah kasa

\begin{tabular}{|c|c|c|c|c|c|c|}
\hline \multirow{2}{*}{ No } & \multirow{2}{*}{ Parameter } & \multirow{2}{*}{ Satuan } & \multirow{2}{*}{ Metode } & \multicolumn{3}{|c|}{ Jenis Tanah } \\
\hline & & & & Tropaquept & Hapludult & Endoaquert \\
\hline 1. & $\mathrm{pH} \mathrm{H}_{2} \mathrm{O}$ & - & $\mathrm{pH}(1: 5)$ & 5,19 & 4,90 & 5,09 \\
\hline 2. & $\mathrm{pH} \mathrm{KCl}$ & - & $\mathrm{pH}(1: 5)$ & 4,86 & 4,19 & 3,95 \\
\hline \multirow[t]{3}{*}{3.} & Pasir & $\%$ & Pipet & 13 & 11 & 7 \\
\hline & Debu & $\%$ & Pipet & 28 & 22 & 15 \\
\hline & Liat & $\%$ & Pipet & 59 & 67 & 78 \\
\hline 4. & $\mathrm{C}$ & $\%$ & Kjeldahl & 2,12 & 1,34 & 1,57 \\
\hline 5. & $\mathrm{~N}$ & $\%$ & Kjeldahl & 0,21 & 0,17 & 0,15 \\
\hline 6. & $\mathrm{C} / \mathrm{N}$ & - & & 10 & 8 & 10 \\
\hline 7. & $\mathrm{P}_{2} \mathrm{O}_{5}$ & $\mathrm{mg} 100 \mathrm{~g}^{-1}$ & $\mathrm{HCl} 25 \%$ & 79,3 & 63,8 & 25,6 \\
\hline 8. & $\mathrm{~K}_{2} \mathrm{O}$ & $\mathrm{mg} 100 \mathrm{~g}^{-1}$ & $\mathrm{HCl} 25 \%$ & 99 & 73 & 55 \\
\hline \multirow[t]{5}{*}{9.} & Kation & & & & & \\
\hline & $\mathrm{K}$ & $\operatorname{cmol}(+) / \mathrm{kg}$ & $\mathrm{NH}_{4} \mathrm{OAc} \mathrm{pH} 7.0$ & 0,36 & 0,17 & 0,17 \\
\hline & $\mathrm{Ca}$ & $\mathrm{cmol}(+) / \mathrm{kg}$ & $\mathrm{NH}_{4} \mathrm{OAc} \mathrm{pH} 7.0$ & 13,60 & 19,44 & 57,93 \\
\hline & $\mathrm{Mg}$ & $\operatorname{cmol}(+) / \mathrm{kg}$ & $\mathrm{NH}_{4} \mathrm{OAc} \mathrm{pH} 7.0$ & 3,80 & 2,98 & 9,7 \\
\hline & $\mathrm{Na}$ & $\operatorname{cmol}(+) / \mathrm{kg}$ & $\mathrm{NH}_{4} \mathrm{OAc} \mathrm{pH} 7.0$ & 0,67 & 0,21 & 0,23 \\
\hline 10. & KTK & $\mathrm{cmol}(+) / \mathrm{kg}$ & $\mathrm{NH}_{4} \mathrm{OAc} \mathrm{pH} 7.0$ & 16,95 & 26,77 & 36,44 \\
\hline 11. & $\mathrm{~KB}$ & $\%$ & & $>100$ & 85 & $>100$ \\
\hline 12. & Fe tersedia & $\mathrm{mg} \mathrm{kg}^{-1}$ & DTPA & 39,72 & 54,39 & 27,03 \\
\hline 13. & Fe total & $\mathrm{mg} \mathrm{kg}^{-1}$ & $\mathrm{HNO}_{3}+\mathrm{HClO}_{4}$ & 32.157 & 38.832 & 22.256 \\
\hline
\end{tabular}

\section{Pertumbuhan Tanaman Padi Sawah}

Pertumbuhan tanaman padi varietas IR 64 meliputi tinggi tanaman dan jumlah anakan yang diamati sampai menjelang panen. Secara visual tanaman padi sampai dengan umur $100 \mathrm{HST}$ pada berbagai jenis perlakuan baik perbedaan jenis tanah dan kadar Fe yang ditambahkan dalam pupuk organik padat menunjukkan pertumbuhan yang baik, hal ini ditunjukkan dalam Gambar 1.

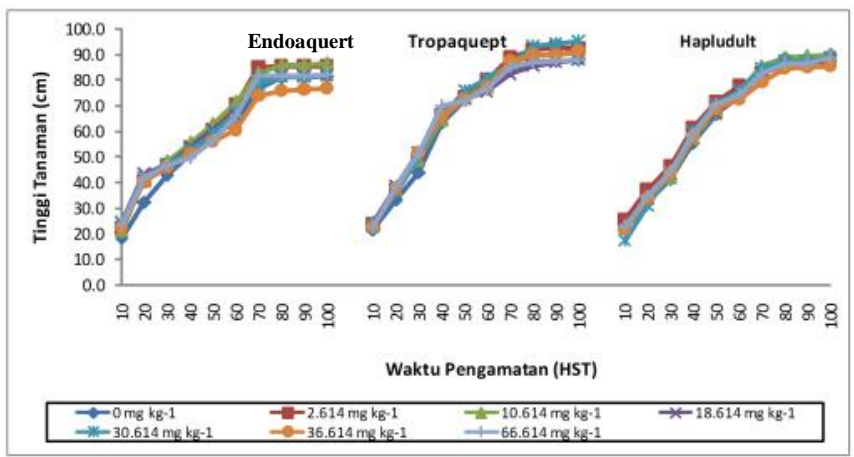

Gambar 1. Tinggi tanaman padi sampai umur 100 HST
Pada Tropaquept, tinggi tanaman lebih baik dibandingkan dengan kedua jenis tanah lainnya yaitu pada Endoaquert dan Hapludult. Perlakuan dengan penambahan pupuk organik padat tanpa penambahan Fe pada ketiga jenis tanah lebih baik dibandingkan dengan kontrol (tanpa penambahan pupuk organik). Hal ini menunjukkan bahwa dengan penambahan bahan organik mengakibatkan lingkungan tumbuh menjadi lebih optimal di dalam mendukung pertumbuhan tanaman.

Jumlah anakan padi varietas IR 64 sampai dengan umur 100 HST terlihat pada Gambar 2. Dari gambar terlihat bahwa pada Tropaquept, jumlah anakan padi lebih banyak dibandingkan dengan Endoaquert dan Hapludult. Jumlah anakan terus meningkat sampai dengan padi umur 70 HST dan cenderung tetap sampai padi menjelang panen. Ini menunjukkan bahwa pada umur padi 70 HST merupakan per- 


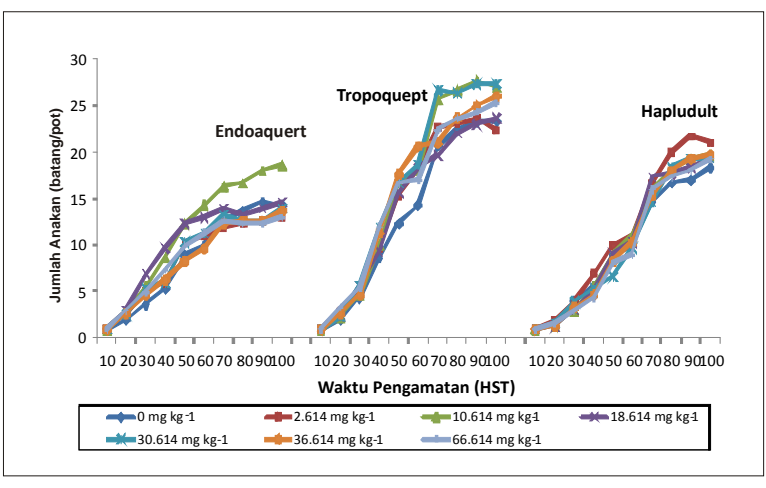

Gambar 2. Jumlah anakan tanaman padi sampai umur 100 HST

tumbuhan maksimum jumlah anakan padi karena pada fase ini tanaman padi tergolong pada fase vegetatif cepat. Setelah umur 70 HST, padi mengalami fase vegetatif lambat yang ditandai dengan beberapa anakan yang mati.

Pada perlakuan penambahan Fe sebanyak 8.000 $\mathrm{mg} \mathrm{kg}^{-1}$ pada Endoaquert dan Tropaquept jumlah anakan lebih baik dibandingkan dengan kontrol (tanpa penambahan pupuk organik padat). Pada Hapludult, perlakuan penambahan organik saja tanpa penambahan Fe menghasilkan jumlah anakan yang lebih baik dibandingkan dengan kontrol (tanpa penambahan pupuk organik padat).

Tabel 3. Produksi tanaman padi

\begin{tabular}{lccc}
\hline \multirow{2}{*}{ Perlakuan } & \multicolumn{3}{c}{ Bobot Kering } \\
\cline { 2 - 4 } & Jerami & Gabah & $\begin{array}{c}\text { Gabah } 1000 \\
\text { butir }\end{array}$ \\
\hline Jenis Tanah & $\ldots \ldots \ldots$ g/pot........ & $\mathrm{g}$ \\
Tropaquept & $28,75 \mathrm{~b}$ & $55,29 \mathrm{a}$ & $25,39 \mathrm{a}$ \\
Endoaquert & $34,74 \mathrm{a}$ & $29,98 \mathrm{c}$ & $22,68 \mathrm{~b}$ \\
Hapludult & $23,06 \mathrm{c}$ & $39,77 \mathrm{~b}$ & $23,52 \mathrm{~b}$ \\
Penambahan Fe dalam pupuk organik $\left({\left.\mathrm{mg} . \mathrm{kg}^{-1}\right)}^{-}\right.$ & & \\
Tanpa pupuk organik & $27,84 \mathrm{a}$ & $42,29 \mathrm{ab}$ & $22,99 \mathrm{a}$ \\
Pupuk organik & $29,42 \mathrm{a}$ & $43,28 \mathrm{a}$ & $24,29 \mathrm{a}$ \\
Pupuk organik + 8.000 Fe & $31,03 \mathrm{a}$ & $46,16 \mathrm{a}$ & $24,27 \mathrm{a}$ \\
Pupuk organik + 16.000 Fe & $23,38 \mathrm{a}$ & $41,86 \mathrm{ab}$ & $23,90 \mathrm{a}$ \\
Pupuk organik + 24.000 Fe & $29,82 \mathrm{a}$ & $41,32 \mathrm{ab}$ & $24,75 \mathrm{a}$ \\
Pupuk organik + 32.000 Fe & $27,76 \mathrm{a}$ & $40,37 \mathrm{ab}$ & $24,21 \mathrm{a}$ \\
Pupuk organik + 64.000 Fe & $27,69 \mathrm{a}$ & $36,48 \mathrm{~b}$ & $22,63 \mathrm{a}$ \\
\hline CV (\%) & 19,77 & 14,23 & 8,23 \\
\hline
\end{tabular}

Angka-angka pada kolom yang sama diikuti huruf yang sama tidak berbeda nyata uji DMRT 5\%. 
Penelitian Hartatik dan Suriadikarta (2012) melaporkan bahwa pengaruh pupuk organik granul dengan kadar Fe sebesar 14.597 mg. kg ${ }^{-1}$ yang ditambahkan tanpa pupuk NPK nyata meningkatkan bobot gabah kering dibanding dengan kontrol. Siavoshi et al., (2011) melaporkan bahwa penggunaan pupuk organik sebanyak 2 t.ha ${ }^{-1}$ berpengaruh nyata terhadap pertumbuhan dan produksi padi.

\section{KESIMPULAN}

1. Pemberian pupuk organik yang diperkaya dengan besi sampai $64.000 \mathrm{mg} \cdot \mathrm{kg}^{-1}$ tidak berpengaruh nyata terhadap pertumbuhan dan produksi tanaman padi.

2. Pemberian pupuk organik pada tanah Tropaquept Sukamandi dapat meningkatkan secara nyata pertumbuhan tanaman padi, bobot kering gabah, dan bobot gabah 1000 butir.

\section{DAFTAR PUSTAKA}

Balai Penelitian Tanah. 2005. Petunjuk Teknis Analisis Kimia Tanah, Air, Tanaman, dan Pupuk. Badan Penelitian dan Pengembangan Pertanian. Departemen Pertanian. Bogor.

Bonsiri, K., D. Suangsang, S. Pirommi, A. Seaang, W. Tongying, J. Kontha and A. Weejitjan. 2009. Effect of granular organic fertilizer on the growth and yield of pak choi and rice $c v$. Phitsanulok 60-2. Asian Journal Food Agro-Industry: 160-163.
Hartatik, W dan D.A Suriadikarta. 2012. Pengaruh pupuk organik granul dan curah terhadap sifat kimia tanah, pertumbuhan, dan produksi padi sawah. Prosiding Seminar dan Kongres Nasional Himpunan Ilmu Tanah Indonesia X. Universitas Negeri Surakarta.

Myint, A.K, T. Yamakawa, Y. Kajihara, and T. Zenmyo. 2010. Application of different organic ang mineral fertolizers on the growth, yield and nutrient accumulation of rice in a Japanese ordinasry paddy field. Science World Journal 5 (2):47-54.

Peraturan Menteri Pertanian No. 70/Permentan/ SR.140/10/2011 Tentang Pupuk Organik, Pupuk Hayati, dan Pembenah Tanah.

Siavoshi, M.A, S.L. Lawere. 2011. Effect of organic fertlizer on growth and yield components in rice (Oryza sativa, L). Journal of Agricultural Science 3 (3): 217-224.

Suhardjo H, Soepartini, dan Kurnia U. 1993. Bahan Organik Tanah. Informasi Penelitian Tanah, Air, Pupuk dan lahan. Bogor: Pusat Penelitian Tanah dan Agroklimat (3): 10-12

Suhartini T. 2004. Perbaikan varietas padi untuk lahan keracunan besi. Balai Besar Penelitian dan Pengembangan Bioteknologi dan Sumberdaya Genetik Pertanian. Buletin Plasma Nutfah (1): 10-15.

Suriadikarta, D.A., T. Prihatini, D. Setyoini, dan W. Hartatik. 2005. Teknologi Pengelolaan Bahan Organik Tanah. Pusat Penelitian dan Pengembangan Tanah dan Agroklimat. Badan Litbang Pertanian, Deptan. 